\title{
Experimental Results from the Active Aeroelastic Wing Wind Tunnel Test Program
}

\author{
Jennifer Heeg, ${ }^{1}$ Charles V. Spain, ${ }^{2}$ James R. Florance, ${ }^{1}$ \\ Carol D. Wieseman, ${ }^{3}$ Thomas G. Ivanco, ${ }^{4}$ Joshua A. DeMoss, ${ }^{5}$ and Walter A. Silva ${ }^{1}$ \\ NASA Langley Research Center, Hampton, Virginia, 23681 \\ Andrew Panetta ${ }^{6}$ \\ SWALES Aerospace, Hampton, Virginia, 23681 \\ Peter Lively ${ }^{7}$ \\ Lockheed Martin Space Operations, Hampton, Virginia 23681 \\ and \\ Vic Tumwa ${ }^{8}$ \\ Jacobs-Sverdrup, Hampton, Virginia 23681
}

\begin{abstract}
The Active Aeroelastic Wing (AAW) program is a cooperative effort among NASA, the Air Force Research Laboratory and the Boeing Company, encompassing flight testing, wind tunnel testing and analyses. The objective of the AAW program is to investigate the improvements that can be realized by exploiting aeroelastic characteristics, rather than viewing them as a detriment to vehicle performance and stability. To meet this objective, a wind tunnel model was crafted to duplicate the static aeroelastic behavior of the AAW flight vehicle. The model was tested in the NASA Langley Transonic Dynamics Tunnel in July and August 2004. The wind tunnel investigation served the program goal in three ways. First, the wind tunnel provided a benchmark for comparison with the flight vehicle and various levels of theoretical analyses. Second, it provided detailed insight highlighting the effects of individual parameters upon the aeroelastic response of the AAW vehicle. This parameter identification can then be used for future aeroelastic vehicle design guidance. Third, it provided data to validate scaling laws and their applicability with respect to statically scaled aeroelastic models.
\end{abstract}

\section{Nomenclature}

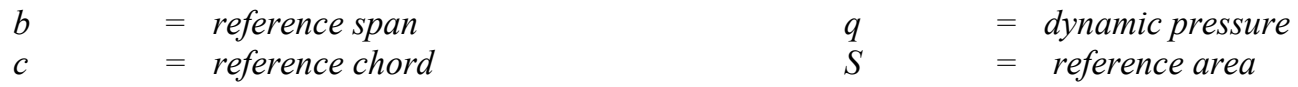

$C_{X Y}=$ coefficient of force or moment X, due to deflection $\mathrm{Y}$

(e.g. $C_{L \alpha}=$ coefficient of lift due to angle of attack), see definitions in tables 1 and 2

$C_{p} \quad=$ pressure coefficient

$\Delta C_{p} \quad=$ delta pressure coefficient $-C_{p}$ (lower)- $C_{p}$ (upper)

${ }^{1}$ Research Engineers, Aeroelasticity Branch, Mail stop 340, Senior members AIAA

${ }^{2}$ Research Engineer, Aeroelasticity Branch, Mail stop 340

${ }^{3}$ Research Engineer, Aeroelasticity Branch, Mail stop 340, Associate fellow AIAA

${ }^{4}$ Research Engineer, Aeroelasticity Branch, Mail stop 340, Member AIAA

${ }^{5}$ Cooperative Education Engineering Student, Aeroelasticity Branch and Virginia Polytechnic Institute and State University, Student member AIAA

${ }^{6}$ Design Engineer, Aeroelasticity Branch, Mail stop 340

${ }^{7}$ Aeronautical Engineer, Mail Stop 230, Member AIAA

${ }^{8}$ Test Engineer, Transonic Dynamics Tunnel, Mail stop 340, Member AIAA 


\section{Introduction}

Aeroservoelastic interactions have historically been viewed as having adverse effects on vehicle stability and performance. Chief among these effects are trailing edge control surface loss of effectiveness and reversal. ${ }^{1}$ Flexible wings with a trailing edge control surface experience competing effects when the control surface is employed downward; additional lift is produced by deflection of the control surface, but the wing also twists nose down, reducing the effective angle of attack of the wing. Reversal is defined when the two contributions balance and control surface deflection produces no net change in lift on the wing, rendering it unable to maneuver using that control surface.

Adverse aeroservoelastic interactions occurred in the development of the F/A-18. ${ }^{2,3}$ The aircraft roll performance declined dramatically in the transonic flight regime, caused by trailing edge control surface reversal. An aircraft modification was implemented to torsionally stiffen the wings by replacing multiple upper and lower skin panels between the rear and aft spars with fewer larger and much stiffer panels. The aft spar was thickened, the aileron was lengthened, and the trailing edge flap was used to assist in rolling the aircraft. Flight testing found that these modifications were insufficient. An additional modification was made to the aircraft to achieve the desired roll performance; the flight control laws were modified, employing the leading edge flaps as roll effectors in the transonic regime.

The Active Flexible Wing (AFW) concept was developed in the 1980s at Rockwell International Corporation, in cooperation with the Air Force Wright Aeronautical Laboratory and the NASA Langley Research Center. ${ }^{4}$ This concept exploited, rather than avoided, wing flexibility to provide weight savings and improved aerodynamics for advanced fighter configurations. The AFW program conducted four wind tunnel tests from 1986 through 1991. These tests demonstrated the usefulness of active controls technology for favorably modifying the aeroelastic response characteristics of a flight vehicle.

The Active Aeroelastic Wing (AAW) program ${ }^{5}$ showcases the potential benefits that a flexible wing offers an aerospace vehicle. The program objective is to investigate the improvements that can be derived from considering aeroelasticity in a beneficial light, rather than as a detriment to vehicle performance and stability. The AAW philosophy contrasts with conventional practice in which wing flexibility is avoided at the cost of added structural weight.

Within the program, flight testing, wind tunnel testing and analyses of various levels of complexity have been and are being performed by engineers and technicians at several partnering organizations. The AAW program was initiated in 1996 by the Air Force. NASA Dryden Flight Research Center (DFRC), the Air Force Research Laboratory (AFRL), the Boeing Aircraft Company (BAC) and NASA Langley Research Center (LaRC) are the primary collaborating organizations for this effort.

A wind tunnel model was crafted to duplicate the static aeroelastic behavior of the AAW flight vehicle; testing was subsequently conducted in the LaRC Transonic Dynamics Tunnel (TDT). The only previous investigation known to the authors that correlates data from flight testing and wind tunnel testing of a static aeroelastically scaled wind tunnel model occurred in the 1960s. The previous investigation focused on a multi-jet cargo airplane; details appear in reference 6 .

The AAW wind tunnel investigation served the program goal in several ways: providing data for comparison with the flight vehicle and with various levels of analysis; investigating aeroelastic vehicle research issues; providing aeroelastic vehicle design guidance; and serving as a testbed for validation of ground to flight scaling methodology.

This paper describes the wind tunnel model and testing, and then compares the experimental results to those obtained from linear analysis and flight.

\section{AAW Aircraft}

\section{Active Aeroelastic Wing Program}

The AAW aircraft is a modified version of a production F/A-18A. The modifications were designed such that the aircraft would mimic the original F/A-18A torsional stiffness. An inboard wing panel was replaced to destiffen the wing, the leading edge control surfaces were modified to be independently actuated, and a research control computer was added. Additional research instrumentation as well as software enhancements for research flight testing were also added to the vehicle. Phase 1 of the flight test program focused on identification of important vehicle parameters which would be necessary for successful development of flight control laws. Using the information from phase 1 and a design philosophy to target aeroelastically induced effects, control laws were designed and benchtested. Phase 2 of the flight test program has begun; its focus is testing of the control laws. 


\section{Wind Tunnel Model}

Scaling

Developing a wind tunnel model to match the static aeroelastic properties of an airplane is different from the process used to match the dynamic aeroelastic properties. In the case of a static aeroelastic wind tunnel model, the important properties are the stiffness and the aerodynamic loads and maintaining the ratio between them. Unlike a dynamic model, the mass and inertia characteristics are not duplicated. Consequently any dynamic data obtained in the wind tunnel will not represent dynamic behavior of the flight vehicle.

The scale factors used here, denoted by $\lambda$ and subscripted with the parameter being scaled, represent the ratio of the wind tunnel model parameter divided by the flight vehicle parameter.

Reference 7 details the development of the scale factors for this model, which will be summarized here. An initial flight test condition was chosen for scaling- Mach 1.2 at 15,000 ft altitude. Assuming standard atmosphere properties, this produced a dynamic pressure of $1204 \mathrm{psf}$. A wind tunnel test condition was chosen to match this condition- Mach 1.2 at a dynamic pressure of $250 \mathrm{psf}$. This established the scale factor on dynamic pressure that is required in order to map points from the flight test to the wind tunnel, $\lambda_{\mathrm{q}}=0.2076$. The length scale factor was next established by forcing a match between the Froude number at the $15,000 \mathrm{ft}$ altitude points and a set of wind tunnel test points in R134a- the wind tunnel test medium- along a line of constant density. Froude scaling equates to the length scale factor being the square of the velocity scale factor. The pertinent velocity scale factor resulted from the previous selections and the establishment of a vehicle altitude at which Froude scaling is desired. The result was a length scale factor, $\lambda_{\mathrm{L}}=0.2609$. The stiffness scale factor was subsequently calculated in reference 7 to be $\lambda_{\mathrm{EI}}=\lambda_{\mathrm{q}} \lambda_{\mathrm{L}}{ }^{4}=0.000962$.

Although the model was designed to be scaled with respect to Froude number for one altitude, the Froude number is not thought to be important for scaling models which have no significant contributions to their behavior due to gravitational loads. ${ }^{8}$ Because the AAW model is mounted to the wall, the majority of the gravitational loads will be carried through the balance. It is also contended that the weight distribution over the wing will produce loads which are not significant in comparison to the aerodynamic loads.

Matching all test points is enabled by the ability of the test facility to independently specify Mach number and dynamic pressure and the assumptions that inertial and gravitational loads are negligible.

\section{Model Design}

The design of the wind tunnel model implemented the above scaling parameters. The design had to match the stiffness distribution and load paths of the flight vehicle and simultaneously meet the wind tunnel model strength criteria. The design concept was to have a contoured center plate with an end-grain balsa wood aerodynamic faring. The contouring of the center plate was the result of an iterative analysis and design process, matching first the structural stiffness properties and then the aeroelastic properties of the flight vehicle. The resultant conceptual design for the center plate is shown in figure 1.

While stiffness of the main wing was achieved via thickness contouring, a similar approach for scaling the stiffness of each control surface was not practical, primarily because of the strength requirements and the internal space required to house the unsteady pressure transducers. These requirements drove the design of control surfaces to be stiff aluminum skins and spars. In order to compensate for this stiffer design and still have the control surfaces deform under load mimicking the static aeroelastic deformation of the flight vehicle, hinge line flexures were added. Flexible yet strong, the flexures connect the hydraulic actuators to the control surface structures. They are rectangular plates made from steel alloy, with geometric dimensions tuned through analysis to deform properly. To fully satisfy model strength requirements, however, the leading edge control surface flexures' dimensions had to be slightly increased beyond those that produced ideal compliance under load.

\section{Model Characteristics}

The AAW wind-tunnel model is a $26 \%$ geometrically scaled right half-span representation of an F/A-18A. Figure 2 is a photo of the model installed in the TDT test section.

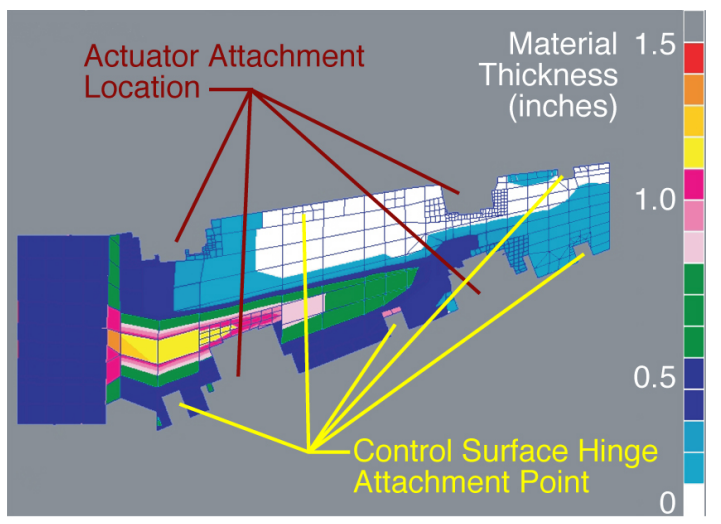

Figure 1. Conceptual design of wing core for AAW wind tunnel model; planform view 
The main wing core is machined from an aluminum billet to have a contoured thickness, simulating the main wing stiffness of the AAW flight vehicle. A balsa wood covering is bonded to the upper and lower surfaces of the main wing structure to provide the proper airfoil shape. The model has four control surfaces, a leading edge outboard (LEO) flap, a leading edge inboard (LEI) flap, a trailing edge outboard (TEO) flap, and a trailing edge inboard (TEI) flap. The control surfaces are attached to the main wing structure through control surface flexures and vane-type hydraulic actuators.

Figure 3 shows a schematic of the AAW model configuration and instrumentation layout. The model is mounted to the tunnel sidewall turntable through a five-component balance used for measuring aerodynamic loads. The turntable is used to set model angle of attack. Two rows of 40 pressure orifices are installed in the wing at roughly $43 \%$ and $87 \%$ of the wing semispan. These ports are instrumented with unsteady pressure transducers. A combination of 14 bending and torsion strain gages were applied to the main wing at the root and 2/3-span (near the wing fold span station of an F/A-18) to determine the loads on the model. Extensive analysis and calibration was employed to optimize the orientation and location of these strain gages to maximize the accuracy of the calculated wing loads from the measured strains. The flap position sensors consist of small torsion beam flexures instrumented with torsion strain gages and attached to each actuator to measure the flap deflection angles. Hinge moments are measured using two bending strain gages mounted to the control surface flexures that attach the flaps to the actuators. Three rows of orifices on the upper and lower surface of the fuselage are used to measure the static pressures on the fairing standoff. An optical-based system called the Videogrammetric Model Deformation (VMD) system ${ }^{9}$ is used to measure the deflection of the wing and control surfaces under aerodynamic load.

The wind tunnel testing of the AAW model was conducted without the canted vertical tail.

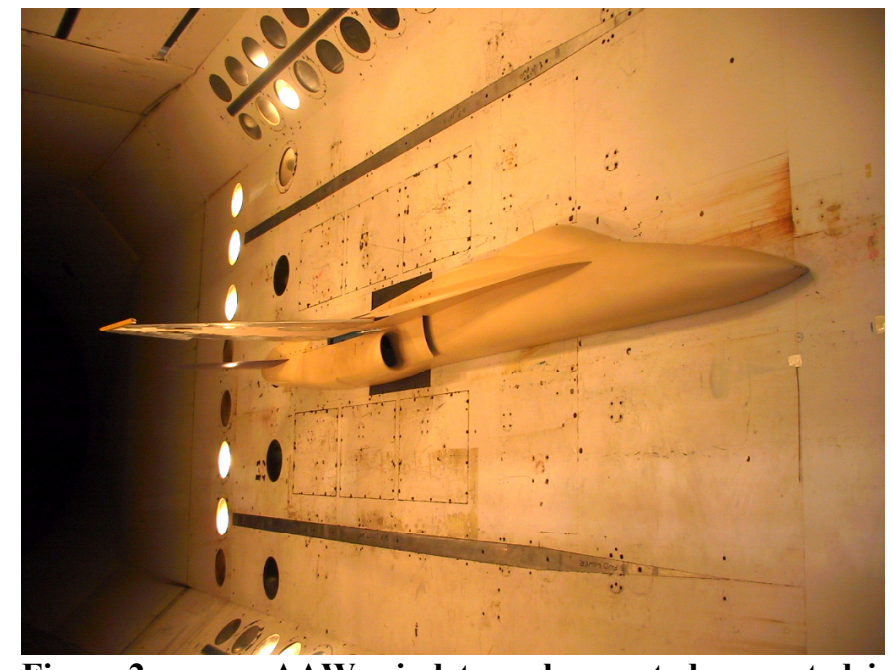

Figure 2. $\quad$ AAW wind tunnel mounted, mounted in the TDT test section

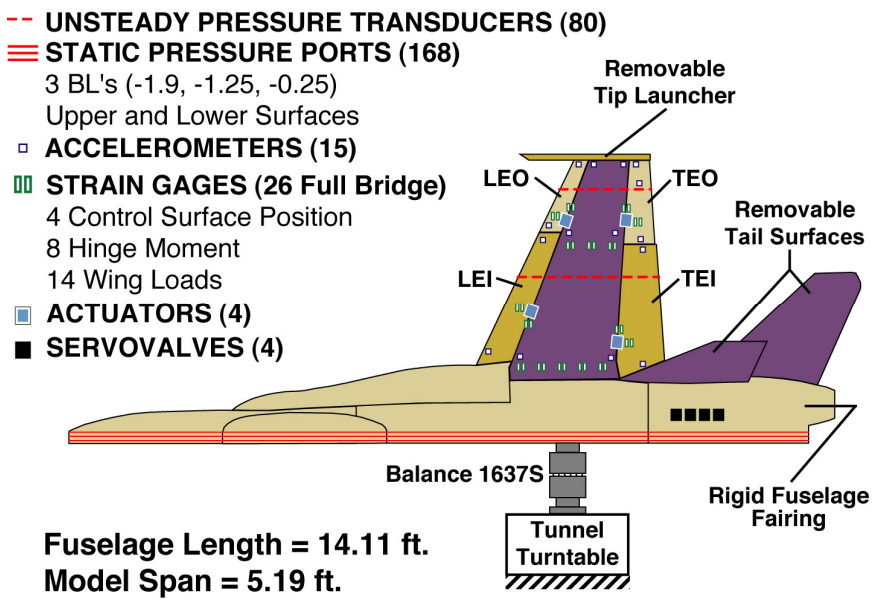

Figure 3. Schematic Planform of AAW wind tunnel model and instrumentation Observations from past testing of the variable stiffness spar (VSS) wind tunnel model ${ }^{10}$ indicated that its nearness to the wall was producing reflections and yawing moment trends which are inconsistent with those experienced by a flight vehicle. In addition to concern about data integrity, the excessive yawing moments experienced by the balance during testing of the VSS model limited the test envelope. Elimination of the vertical tail eased that load sufficiently at the desired test conditions.

\section{Test Facility}

The Transonic Dynamics Tunnel (TDT) is a closed-circuit reduced-pressure tunnel located at sea level. Testing is conducted in two test mediums: air and R134a heavy gas. Higher density and lower speed of sound associated with the heavy gas enable more latitude in model construction. Variable pressure capability and fan motor control allow specification of both Mach number and dynamic pressure. 


\section{Test Matrices}

\section{Testing and Analyzing the AAW Wind Tunnel Model}

The matrices of conditions at which the wind tunnel measurements were made are shown in figure 4, overlaid with the TDT test envelope for R134a. The test conditions envelope shows the combinations of Mach number and dynamic pressure for each test point. There are 4 matrices of test conditions, serving different purposes and denoted A, B, C, and D.

Each wind tunnel test condition in matrix A maps to a flight test condition. The mapped wind tunnel test conditions were generated to correspond to conditions actually flown. At the time of the wind tunnel test, flight test data was not yet available at Mach 1.1, so the planned flight test conditions were used to define wind tunnel test conditions at that Mach number. At each of the conditions in test matrix A, polars were sequentially performed for the angle of attack and control surface deflection angles. Additionally, parameters from each flight test point at the trimmed condition were reproduced on the wind tunnel model and a corresponding data set was obtained. Data sets obtained at these conditions provide the correlation data for the flight vehicle and analyses. At several conditions, combinations of control surface deflections and larger amplitude deflections were obtained. These data sets will be used to evaluate the linearity of larger and combined control surface deflections.

Test matrix B contains a subsonic data set, Mach .85 , and a supersonic data set, Mach 1.1. Data was acquired at $10 \mathrm{psf}$ increments in dynamic pressure at both of these Mach numbers. This provided data sets for evaluating the influence of increasing aeroelastic feedback, without a simultaneous change in the applied aerodynamic pressure distribution. At each of these test points, inboard and outboard trailing edge control surface polars were performed to examine the control surface reversal issue in detail. Angle of attack polars were performed to examine leading edge control surface divergence.

Test matrix $\mathrm{C}$ contains a subset of test conditions from test matrix A. At each of these test conditions, each of the four control surfaces was oscillated individually, at several discrete frequencies. Combinations of adjacent and tandem control surfaces were also performed at several frequencies. The relative phasing of the control surfaces was varied, moving them synchronously, with each control surface leading the other by a quarter cycle, or out of phase.

Test matrix D was conducted in air, in contrast to matrices A, B and C, all of which were conducted in R134a. The test conditions were generated to test a theory of transonic similarity. In test matrix D, there are pairs of points which correspond to a test condition in R134a. Each pair contains a point that matches the Mach number of its R134a companion point. Each pair also contains a point where the Mach number has been determined based on transonic similarity parameters arising from transonic aerodynamic small disturbance theory. ${ }^{11}$

\section{Conventions}

The stability and control derivatives discussed here represent a subset of those produced by the wind tunnel test and a small subset of those produced by the flight test and analyses. Because the model is only statically scaled, the coefficients discussed are only the static stability and control derivatives. Fourteen coefficients will be discussed in this paper; lift and pitching moment each due to angle of attack and deflection of the four control surfaces; and rolling moment due to deflection of the four control surfaces. The force and moment sign conventions utilized in the comparisons of stability and control derivatives are listed in table 1. The deflection sign conventions are given in table 2. Positive deflection of all control surfaces are defined as the free edge down for the symmetric derivatives. For the antisymmetric derivatives, leading edge control surfaces are positive free edge down and 
trailing edge control surfaces are positive free edge up. Although each model and each component of the AAW program had a unique axis system and deflection definition set, all of the data sets have been converted to use the listed conventions.

\begin{tabular}{|l|c|c|l|}
\hline \multicolumn{1}{|c|}{ Quantity } & Symbol & Nondimensionalization & \multicolumn{1}{c|}{ Definition of Positive } \\
\hline Lift force & $\mathrm{L}$ & $1 /(\mathrm{qS})$ & UP \\
\hline Pitching moment & $\mathrm{m}$ & $1 /(\mathrm{qSc})$ & Nose UP \\
\hline Drag force & $\mathrm{D}$ & $1 / \mathrm{qS}$ & Downstream \\
\hline Rolling moment & $\mathrm{I}$ & $1 /(\mathrm{qSb})$ & Right wing UP \\
\hline Yawing moment & $\mathrm{n}$ & $1 /(\mathrm{qSb})$ & Nose out of wall, or nose right \\
\hline Side force & $\mathrm{s}$ & $1 /(\mathrm{qS})$ & Out of wall, or out the right wing \\
\hline
\end{tabular}

Table 1. Conventions for forces and moments

\begin{tabular}{|l|l|c|c|}
\hline Quantity & $\begin{array}{l}\text { Symbol, } \\
\text { Subscript }\end{array}$ & Symmetric Deflection & Antisymmetric Deflection \\
\hline Angle of attack & $\alpha$ & +nose up & \\
\hline Leading edge inboard deflection & $\delta_{\mathrm{LEI}}$ & + free edge $\downarrow$ & + free edge $\downarrow$ \\
\hline Leading edge outboard deflection & $\delta_{\mathrm{LEO}}$ & + free edge $\downarrow$ & + free edge $\downarrow$ \\
\hline Trailing edge inboard deflection & $\delta_{\mathrm{TEI}}$ & + free edge $\downarrow$ & + free edge $\uparrow$ \\
\hline Trailing edge outboard deflection & $\delta_{\mathrm{TEO}}$ & + free edge $\downarrow$ & + free edge $\uparrow$ \\
\hline
\end{tabular}

Table 2. Conventions for deflections

\section{Linear Analysis}

\section{Linear modeling and analysis of the AAW wind tunnel model}

Two structural finite element models (FEM) were utilized in the AAW program- one represented the wind tunnel model and one represented the flight vehicle. The FEM for the wind tunnel model is described below. The flight vehicle FEM was provided by the Boeing Aircraft Company and is detailed in reference 11. This paper presents minimal results obtained from linear analysis of the flight vehicle.

The wind tunnel model FEM represented, to the extent practical, the actual materials and hardware used in the model construction. Details of the FEM evolved as the design and fabrication progressed. The model's structural concept and therefore the FEM were driven largely by strength and flexibility requirements.

Figure 5 is an image of the exterior of the final FEM. Note that the FEM is a left-half model to correspond with the Flight Vehicle FEM. The Flight Vehicle was the basis for the stiffness distribution designed into the windtunnel model via aeroelastic scaling laws and the wind tunnel model FEM.

The model stiffness distribution is largely determined by the thickness distribution of the wing aluminum core, which was shown in figure 1. This core thickness resulted from tuning based on achieving bending and twist response to static loads corresponding to the center wingbox of the flight vehicle FEM.

Linear computational aeroelastic analyses were performed using MSC Nastran ${ }^{12}$. Doublet lattice aerodynamic theory ${ }^{13}$ was employed at the subsonic conditions; ZONA51 aerodynamic theory ${ }^{14}$ was employed at supersonic

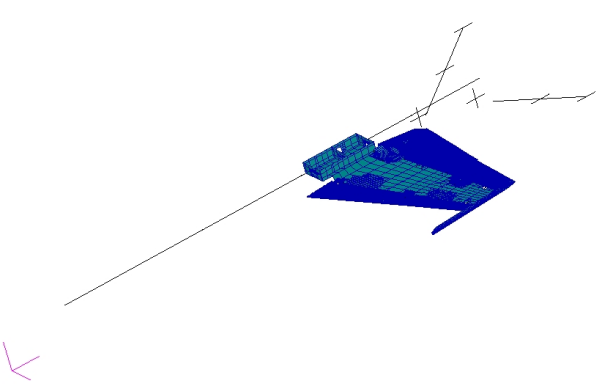

Figure 5. FEM of wind tunnel model

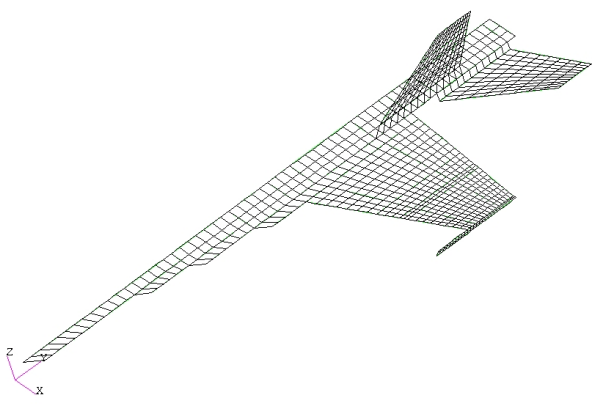

Figure 6. Aerodynamic box layout of wind tunnel model for linear analysis 
conditions. Figure 6 shows the linear aerodynamic model used in the aeroelastic analyses.

Note that the structural and aerodynamic models contain representations of the wing, fuselage, horizontal tail and vertical tail. The stiffness of each component represents the stiffness of the as-built wind tunnel model component. The fuselage and tails are significantly stiffer than those of the flight vehicle.

\section{Stability \& control derivatives}

\section{Experimental Results \& Discussion}

In this paper, three data sets are presented: rigid linear aeroelastic analysis of the wind tunnel model, aeroelastic linear analysis of the wind tunnel model and wind tunnel experimental data. The stability and control derivatives were computed for the wind tunnel model at each of the points in the test matrices shown in figure 4. The wind tunnel model is a semispan model, mounted to a side wall balance that simultaneously measures five components of the acting forces and moments. Unlike a full-span vehicle or model, the longitudinal and lateraldirectional derivatives due to a given control surface are produced from a single set of deflections, making the assumption of symmetry and antisymmetry. The reference point for the rolling moment is the centerline of the flight vehicle; the reference point for the pitching moment is approximately at the wing root quarter chord.

Each of the fourteen static stability and control coefficients are plotted as functions of Mach number in figure 7 , showing all three of the considered data sets. For clarity, data is shown only for the conditions representing an altitude of 10,000 ft. Figure 8 shows the lift coefficients due to control surface deflections plotted as functions of dynamic pressure, grouped by Mach number. Only linear aeroelastic analysis and experimental results for the wind tunnel model are included in this figure. The vertical scales are identical for each of the subplots in figure 8 for a direct comparison of the effectiveness of the four control surfaces.

The control derivatives' behaviors are governed by several factors: the primary wing's aeroelastic characteristics, the flow field in which the control surface operates and the stiffness properties of the control surface and its attachment to the primary wing.

Many of the derivatives are discussed individually in the following sections. A few general statements can be made after examination of the stability and control derivatives.

All of the coefficients show variation induced by both Mach number and dynamic pressure. The changes induced by Mach number reflect the effects of compressibility- changing the aerodynamic load distribution. Present in most of the derivatives' behavior is evidence of a phenomenon labeled 'tuck', which refers to a rapid change in the location of the aerodynamic center with small changes in the Mach number. ${ }^{15}$ The changes induced by the dynamic pressure primarily reflect the effects of flexibility- changing the magnitude of the aerodynamic load relative to structural stiffness. Because of the aeroelastic coupling, the two effects can not be completely dissected.

The most distinctive changes in the coefficients are generally driven by the Mach number, as the flow transitions from subsonic to supersonic. The Mach numbers at which transition begins and ends vary among the three data sets, vary depending upon which coefficient is under consideration and vary by altitude. Experimentally, the wind tunnel coefficients which exhibit sharp changes generally do so between Mach 0.9 and 0.95 . The analytical results show the sharp changes occurring between the analyses performed at Mach 0.95 and those performed at Mach 1.1. Recall that these two cases are analyzed with different aerodynamic theories.

More subtle, yet more consistent changes occur in all of the coefficients as functions of dynamic pressure, analyzed while holding Mach number constant. The trailing edge control surfaces have declining coefficients as the dynamic pressure increases towards the reversal condition, while the leading edge control surfaces have increasing coefficients as dynamic pressure increases. Comparing the slopes of each coefficient for different Mach numbers, it is observed: 1) the trailing edge control surfaces' effectivenesses are more sensitive to dynamic pressure subsonically than supersonically; 2) the leading edge control surfaces' effectivenesses are more sensitive to dynamic pressure supersonically than subsonically.

The linear analysis results generally correlate better with the wind tunnel data at subsonic conditions, as compared to the supersonic conditions. The linear analysis overpredicts the control surface effectiveness in the cases of all control surfaces except for the leading edge inboard. 


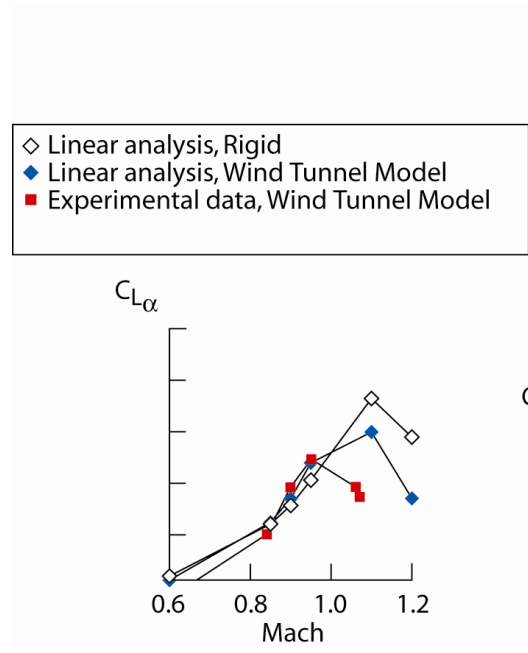

a) Lift derivatives

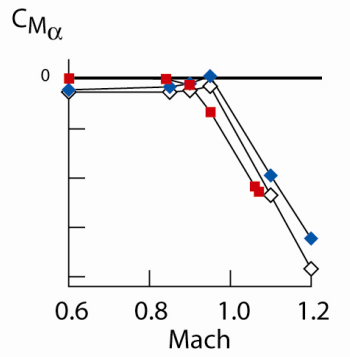

b) Pitching moment derivatives
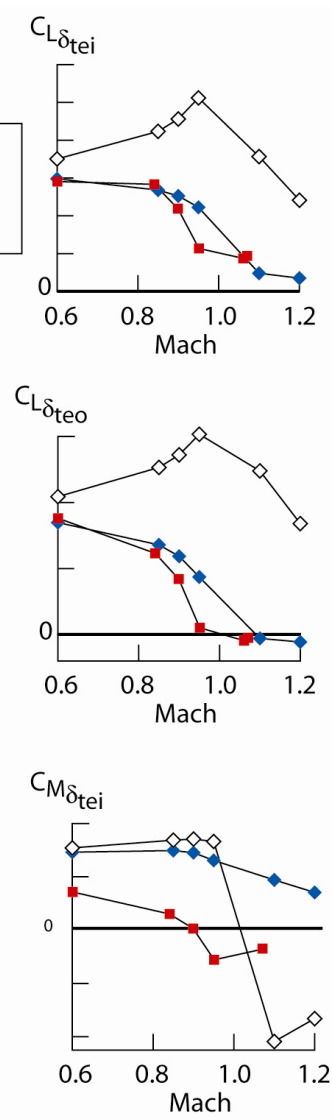

$\mathrm{C}_{\mathrm{M}_{\delta_{\text {teo }}}}$

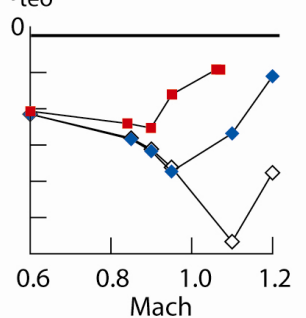

$\mathrm{C}_{\mathrm{M}_{\delta_{\mathrm{le}}}}$

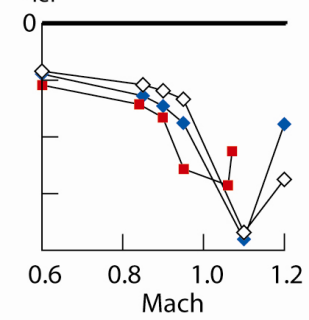

$\mathrm{C}_{\mathrm{M}_{\delta_{\text {leo }}}}$

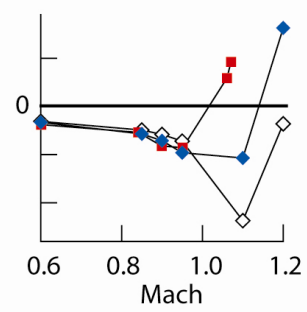

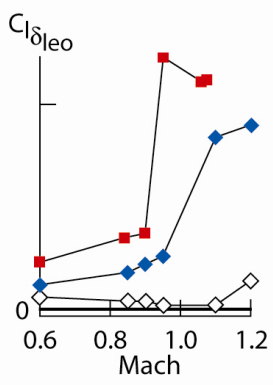
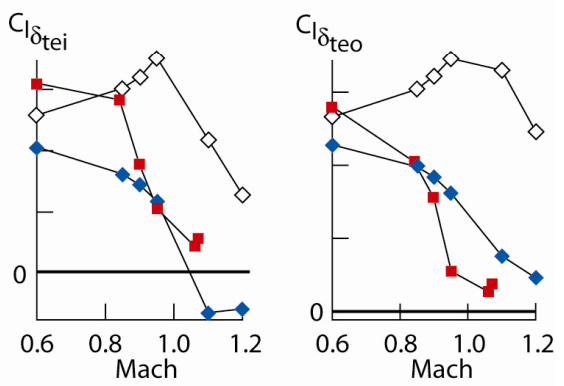

c) Rolling moment derivatives

Figure 7. Stability and control derivatives at 10,000 feet altitude 

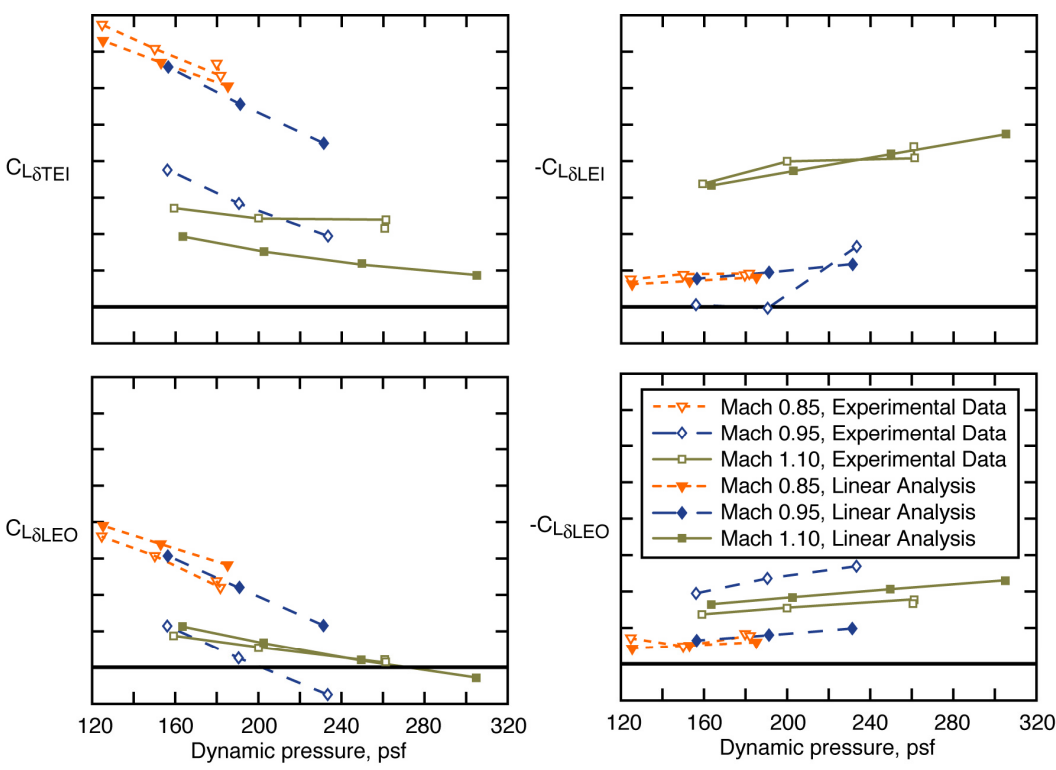

Figure 8. Lift derivatives of wind tunnel model, Experimental and analytical data as functions of dynamc pressure, vertical scales identical

\section{Lift derivatives due to control surface deflections}

Transitioning from subsonic to supersonic causes a distinct change in characteristics of the control derivatives. Trailing edge control surfaces lose effectiveness and in some cases, the derivatives change sign. Leading edge control surfaces, however, gain effectiveness. The experimental data sets show a more gradual transition from subsonic to supersonic than the linear theory predicts, indicating that at high subsonic and low supersonic conditions, the experiments' flow fields contain a mixture of subsonic and supersonic flow regions.

The linear analysis results show large differences between some of the rigid and flexible coefficients. While the angle of attack derivative curves look similar in character for the rigid and flexible coefficients, most of the control derivatives do not. This emphasizes the need to model the aeroelastic behavior to produce trailing edge control surface derivatives. It also emphasizes the need to properly model the stiffness of the connections between the control surface and the primary wing. In contrasting the leading edge and trailing edge control surface derivatives, the flexible leading edge control surface derivatives resemble their rigid counterparts much more closely than the trailing edge control surface derivatives because the leading edge control surfaces are connected to the wing by larger and thicker; therefore stiffer, components. This is necessitated by the large aerodynamic loads that the leading edge control surfaces must transmit without structurally failing or diverging.

$C_{L \alpha} \quad$ For the wind tunnel model data and the linear analysis, the shapes of the lift curve slope variation with Mach number resemble those found in text books discussing compressibility effects- increasing as the Mach number approaches Mach 1 and declining as the Mach number supersonically increases away from 1. Linear analysis results are shown in figure 9 for the rigid wind tunnel model and rigid flight vehicle and the aeroelastic wind tunnel model and aeroelastic flight vehicle. Results for the two rigid configurations are nearly identical, as their aerodynamic box layouts are very similar. For the wind tunnel model, incorporating the aeroelastic effects does not cause as large of a change as that observed in the aeroelastic analysis of the flight vehicle. There are discrepancies between the flight vehicle analyses and the wind tunnel aeroelastic analyses. Recall that the wind tunnel model's fuselage and horizontal tail are rigid relative to those of the flight vehicle. The discrepancies result from reduced flexibility of the wind tunnel model fuselage and tail surfaces.

$\mathrm{C}_{\text {LSTEI }}$ In comparison with the linear analysis, the experimental data shows a downward shift in the coefficient at a lower Mach number. The linear analyses exhibit general trends consistent with those of the experimental data, but

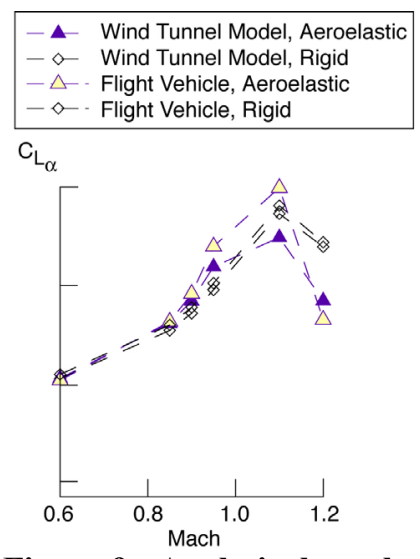

Figure 9. Analytical results for lift curve slope, $10.000 \mathrm{ft}$ 
consistently overpredict the effectiveness of the control surface at any given Mach number. The largest deviation is again at Mach 0.95. At Mach 0.95, the variation with dynamic pressure is well predicted by linear analysis, as shown by the agreement of the slopes in figure 8; the magnitude, however, is not well-predicted. Linear analysis predicts that the trailing edge inboard control is more than twice as effective as indicated by the experimental data.

$\mathrm{C}_{\text {LSTEO }}$ The lift coefficient due to trailing edge outboard control surface deflection reverses at 10,000 feet between Mach 0.95 and Mach 1.1, as indicated in figure 7a. At lower altitude, the reversal occurs at a lower Mach number. The data is more easily interpreted by examination of data at a constant Mach number, plotted as a function of dynamic pressure, figure 8 . At the lower subsonic conditions, data was not acquired at high enough dynamic pressures to produce reversal, but the slopes of the data are linear and have been used to extrapolate reversal dynamic pressures. Supersonically, the trend with dynamic pressure appears asymptotic to 0 effectiveness rather than crossing 0 . The linear analysis shows that there is still plenty of authority at Mach .95 , approximately $50 \%$ of the rigid value. By contrast, the experimental data has reversed by this point.

$C_{L \delta L E I} \quad$ A comparison of the wind tunnel model data to the linear analysis data reveals that the variations with dynamic pressure are very well predicted for all Mach numbers, with the exception of Mach .95; the effect of flexibility on this derivative is well captured with linear analysis. The analytical and experimental data sets show that at supersonic conditions, this control surface increases its authority more rapidly with increasing dynamic pressure than at the subsonic conditions.

$C_{L \delta L E O} \quad$ The leading edge outboard control surface exhibits a different trend than the leading edge inboard control surface; it is more sensitive to dynamic pressure influences at subsonic Mach numbers. This control surface appears to be the most effective at Mach 0.95. This is true for the wind tunnel data for all altitudes where data was acquired. As with the leading edge inboard derivative, the Mach .95 data is the only data that is not well-predicted by the linear analysis.

\section{Pitching moment derivatives:}

The primary indication from the pitching moment derivatives, figure $7 \mathrm{~b}$, is that the pitching moment reference point is very near the subsonic aerodynamic center. Additionally, an effect of deflecting the control surfaces is to shift the acting center of pressure forward and aft, resulting in sign changes for some of the pitching moment control derivatives. Choosing a different reference point changes the character of all of the pitching moment curves.

$\mathrm{C}_{\mathrm{M \alpha}} \quad$ The shape of the curves as functions of Mach number are consistent for all data sets. The subsonic value for this coefficient is near zero for each of the data sets, indicating that the moment reference point is very near the aerodynamic center of the vehicle. The wind tunnel model has very small positive values of $\mathrm{C}_{\mathrm{M} \alpha}$ below Mach .85, indicating that pitching moment reference point is just aft of the aerodynamic center. The magnitude of pitching moment coefficient attains a large negative value as the Mach number changes from subsonic to supersonic. This corresponds to an aft shift in the aerodynamic center.

$\mathrm{C}_{\text {MSTEl }} \quad$ The trends in this coefficient are not well predicted by linear analysis. The sign of the derivative changes for the experimental data, but not for the analysis. For the majority of data points, $\mathrm{C}_{\text {MSTEI }}$ has the opposite sign experimentally and analytically. This indicates that the fore-aft shift in the pressure distribution caused by the trailing edge inboard control surface deflection is not properly captured in the linear analysis.

$\mathrm{C}_{\text {MбTEO }}$ This coefficient does not change sign with Mach number, but the trend in behavior is markedly different in the subsonic and supersonic ranges. For the wind tunnel data and the linear analysis, subsonically, the effectiveness in pitch increases, whereas it decreases supersonically. The trends in this coefficient are not well predicted by linear analysis. The sign of the derivative changes for the experimental data

$\mathrm{C}_{\text {MSLEI }}$ The behavior of this coefficient is similar to that of $\mathrm{C}_{\text {MSTEO }}$ for the wind tunnel model and the linear analysis.

$\mathrm{C}_{\text {MSLEO }} \quad$ The leading edge outboard control surface effectiveness changes sign subsonically, compared to supersonically for the experimental data. Subsonically, a larger control surface deflection causes a smaller change in the pitching moment. Supersonically, a larger control surface deflection causes a larger change in the pitching moment. $\mathrm{C}_{\text {LILEO }}$ is larger for the supersonic conditions than for the subsonic conditions, but the sign of the derivative does not change. This leaves only the moment arm as the cause of the sign change; subsonically, larger pressures are located closer to the pitching moment reference point than they are at the supersonic conditions.

\section{Rolling moment derivatives:}

The rolling moment derivatives' behavior, figure 7c, resembles the lift derivatives' behavior once differences in sign conventions have been included in the interpretations. The rolling moment due to the leading edge control 
surface deflections have sudden changes as the Mach number increases from subsonic to supersonic, whereas the trailing edge control surfaces exhibit gradual declines in effectiveness towards reversal. Rolling moment reversal is discussed more thoroughly in the next section.

$\mathrm{C}_{\text {ISTEI }} \quad$ The linear analysis shows a smaller change in effectiveness than the experimental data, subsonically, and overpredicts the strength of the reversal supersonsonically.

$\mathrm{Cl}_{\text {STEO }} \quad$ In contrast with the inboard control surface, the trailing edge outboard control surface of the wind tunnel model reversed experimentally at 5000. Similar to the trend seen for $\mathrm{C}_{\mid \mathrm{I \delta TEI}}$, the wind tunnel model has a higher effectiveness at the low Mach numbers than shown by the linear analysis.

$\mathrm{Cl}_{\delta L E I} \quad$ This coefficient increases dramatically as the Mach number changes to supersonic. As with $\mathrm{Cl}_{\delta \mathrm{LEI}}$, the trends with dynamic pressure are well-predicted by linear analysis, although the absolute magnitude is not. There are several points at which this coefficient changes sign, reversing.

$\mathrm{Cl}_{\delta L E O} \quad$ This coefficient also increases dramatically as Mach number becomes supersonic. The linear analysis underpredicts the effectiveness of this control surface at every condition.

\section{Reversal data at constant mach number}

The coefficients for lift and rolling moment due to trailing edge outboard control surface deflection are plotted for Mach .85 and 1.1 as the dynamic pressure is increased, figure 10. From this plot, several observations are made.

At mach 1.1, the lift reverses slightly ahead of the rolling moment. Based on extrapolations, the Mach .85 data will likely exhibit this same trend.

The Mach 1.1 derivatives start at lower overall coefficient values than the Mach .85 derivatives. This indicates that the control surfaces are less effective in producing rolling power at the supersonic conditions.

The Mach 1.1 derivatives reverse prior to the Mach .85 derivatives. However, the mach .85 derivatives appear to be more sensitive to dynamic pressure; the slopes of the curves are higher for the Mach .85 derivatives. This indicates that after reversal, the control surfaces would produce more power at the subsonic Mach numbers than at the supersonic mach numbers, just as they do at low dynamic pressures.

The slope of the lift derivative at Mach 1.1 is more erratic than lift derivative at Mach .85 .

Reversal of the rolling moment derivative thus implies one or both of the following: 1) the change in the amount of lift being produced by a control surface has changed sign. For example, a downward trailing edge control surface deflection has caused an increase in

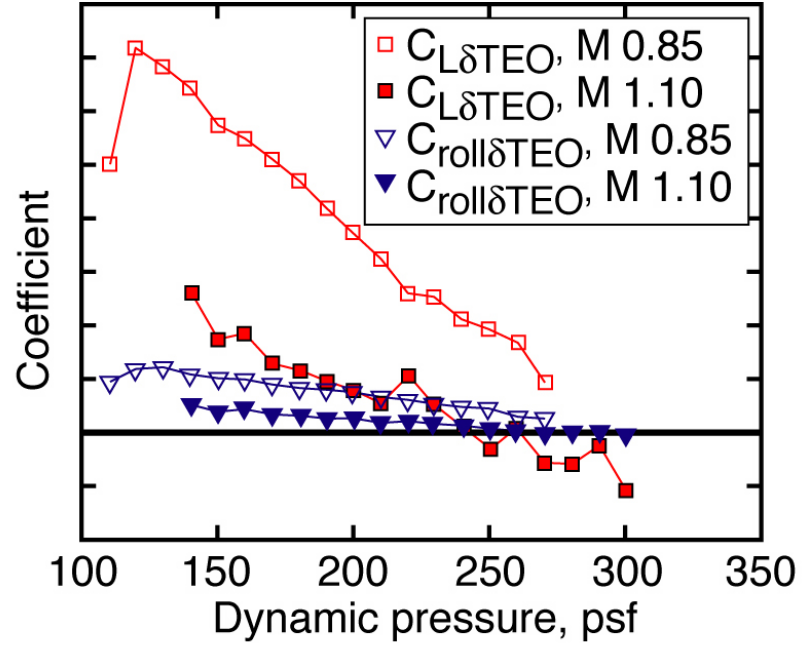

Figure 10. Reversal trends of trailing edge outboard control surface

the lift due to its deflection and the effective increase in camber, but the wing has also twisted nose-down, decreasing the overall wing section angle of attack, causing a decrease in lift. When these two offset, this constitutes lift reversal and can also constitute rolling moment reversal in some instances. 2) the change in the moment arm has changed sign. That is, the change in the lift vector location can move outboard or inboard. If it moves in one direction, the rolling moment derivative has one sign. If it moves in the other direction, the rolling moment derivative has the opposite sign. Thus, in addition to the considerations for lift reversal, the inboardoutboard motion of the center of pressure is important in the behavior of the rolling moment derivatives. Note that there is no requirement for a 3-dimensional wing to reverse in roll at the same dynamic pressure as it reverses in lift, although the two are often close together. 


\section{Percent differences between wind tunnel test data and flight test data}

The Mach number and dynamic pressure combinations in test matrix A, (refer to figure 4), correspond to points in the flight test data or the flight test plan. Figure 11a shows the thirteen points in the flight test envelope that were matched by wind tunnel test conditions to within $2.5 \%$ in Mach number and scaled dynamic pressure. In the case of figure 11a, the size of the circles marking the Mach-altitude combination have no significance. In figures $11 \mathrm{~b}$ through 13f, the size of the circles correspond to the percent differences between quantities obtained from the flight vehicle compared to those quantities obtained from the wind tunnel data.

Each of the plots in figures $11 \mathrm{~b}$ through $11 \mathrm{f}$ contain circles of varying radius at each of the test points shown in figure 11a. The radius of each circle indicates the percentage difference- a larger circle indicates a larger difference between the flight vehicle data and the wind tunnel model data. Negative values of the percent difference mean that the flight vehicle quantity is greater than the wind tunnel model; they are shown in the figure by open, unfilled, symbols. Positive values, shown by filled symbols indicate that the flight vehicle quantity is less than the wind tunnel quantity.

Figure 11b compares the Froude numbers which will be discussed in the subsequent section. Figures 11c through 11f compare the lift force control derivatives; the radii of the circles on all of these plots have been given a consistent scale so the results can be compared for all control surfaces. From these plots, the following observations are made. The trailing edge inboard data provides the best match between flight data and wind tunnel data for all conditions. The trailing edge outboard wind tunnel data overpredicts the flight test data for all conditions. The leading edge inboard wind tunnel data provides significantly better matches to the flight test data at supersonic conditions than at subsonic conditions. Aside from the general grouping of the leading edge inboard data into subsonic and supersonic categories, the percent differences between flight vehicle control derivatives and wind tunnel control derivatives follow no pattern with Mach number or altitude.

\section{Validity of Froude number neglect in test point mapping and data comparison}

One of the assumptions made in determining the wind tunnel model scale factor and test conditions was that the Froude number does not play a significant role in determining the static aeroelastic behavior. The wind tunnel model was Froude scaled to the flight vehicle for an altitude of $15,000 \mathrm{ft}$. That is, for each mach number at 15,000

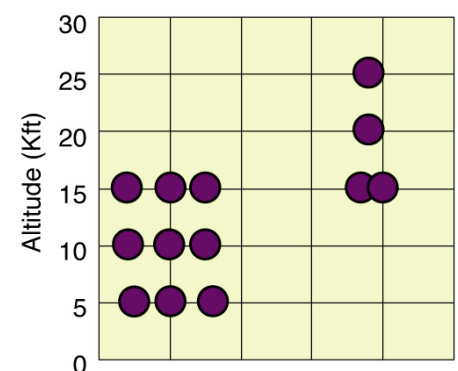

a) Test conditions, no differences represented

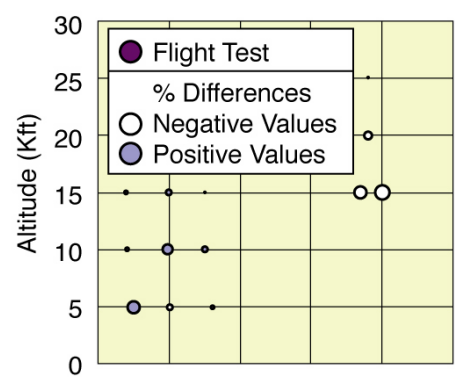

c) \% Difference in $\mathrm{C}_{\mathrm{\delta}_{T} \text { TEl }}$

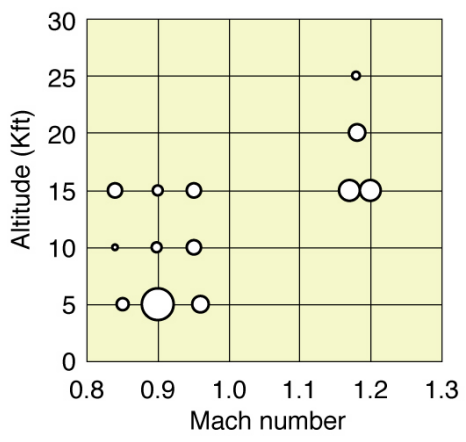

e) \% Difference in $\mathrm{C}_{L_{\delta}}{ }_{\text {TEO }}$

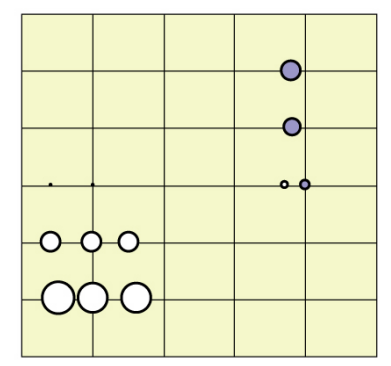

b) $\%$ Difference in Froude number

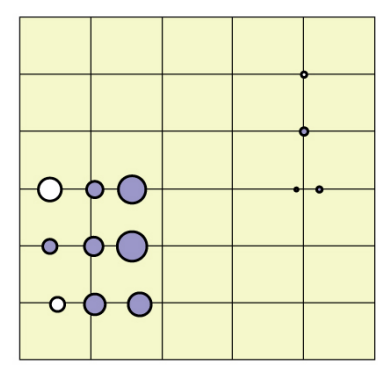

d) \% Difference in $C_{L_{L E l}}$

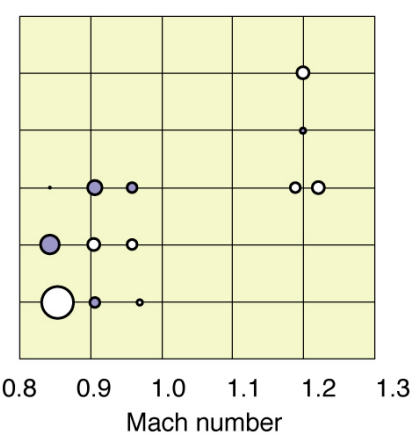

f) \% Difference in $C_{L_{L E O}}$

Figure 11. Percent differences between flight test results and wind tunnel test results

The Froude number plot, figure $11 \mathrm{~b}$, shows the percentage difference of the wind tunnel test point relative to the point required for Froude scaling the flight vehicle. A value of 0 , or a small radius circle means that the point is a better Froude scale match to the flight vehicle at that condition. The data shows that the test points at $15 \mathrm{Kft}$ are approximately Froude scaled. There is a small amount of variation with mach number because the flight test altitude varied slightly and the wind tunnel test condition wasn't adjusted to account for the variation. As the altitude increases or decreases, the Froude scaling is increasingly invalid. 
If Froude scaling is important to the model, or to a single parameter, it is expected that the difference in the parameter will resemble the distribution of the difference in the Froude number- the errors will be smallest at $15 \mathrm{Kft}$ and increasingly large as the condition moves away from $15,000 \mathrm{ft}$. This assumes that the errors are proportional to the Froude number mismatch and that there are no other changeable errors in the data. This is a gross assumption.

None of the differences in the coefficients follow the pattern of the Froude number mismatch. The percentage differences between flight data and wind tunnel data are random relative to the Froude number mismatch. Thus is it shown to be likely that the Froude number bears no importance in reproducing the static aeroelastic control derivatives for this side wall mounted wind tunnel model

\section{Pressure Data}

Steady pressure information was computed by taking the mean value of 5 seconds of data from the unsteady pressure transducer measurements. Experimental data is plotted in figure 12 at test conditions equivalent to $15000 \mathrm{ft}$ altitude. The pressure coefficients are shown for the upper wing surface at the outboard pressures station, $87 \%$ wing semispan.

The pressures fit into three groups: subsonic, supersonic and dominated by mixed flow. The subsonic pressure distributions have lower leading edge pressure peaks which terminate near the leading edge control surface hinge line. The supersonic distributions have a larger amplitude; the pressures gradually decrease with increasing chord-wise coordinate, extending aft to the trailing edge control surface hinge line. A second dominant characteristic of the pressure distributions is the pressure hump in the vicinity of the trailing edge control surface hinge line. The hump is opposite in sign to the leading edge pressure spike and generally smaller in magnitude. Subsonically, the humps at subsonic conditions are slightly ahead of the humps at supersonic conditions.

The Mach 0.95 pressure distribution over the leading edge control surface resembles the subsonic pressure distribution in that region. Moving aft on the wingbox, the Mach .95 pressure coefficient has larger magnitude than either the subsonic or the supersonic data. The trailing edge hinge line hump is located at the same chord station as the supersonic cases, but the magnitude is significantly higher. As the trailing edge is approached, the pressure returns to the same value as the pressure at subsonic conditions.

Linear analysis shows that at subsonic conditions, the pressure distributions look very simple; a leading edge pressure spike dominates, as shown by the differential pressure coefficient, $\Delta \mathrm{Cp}$, carpet plot in figure 13 for Mach 0.85 at a dynamic pressure of $182 \mathrm{psf}$. Also shown in the plot are experimental $\Delta \mathrm{Cp}$ values at the two span stations where pressures were measured. The leading edge control surfaces act in the flow field in the region of a high pressure gradient. The trailing edge
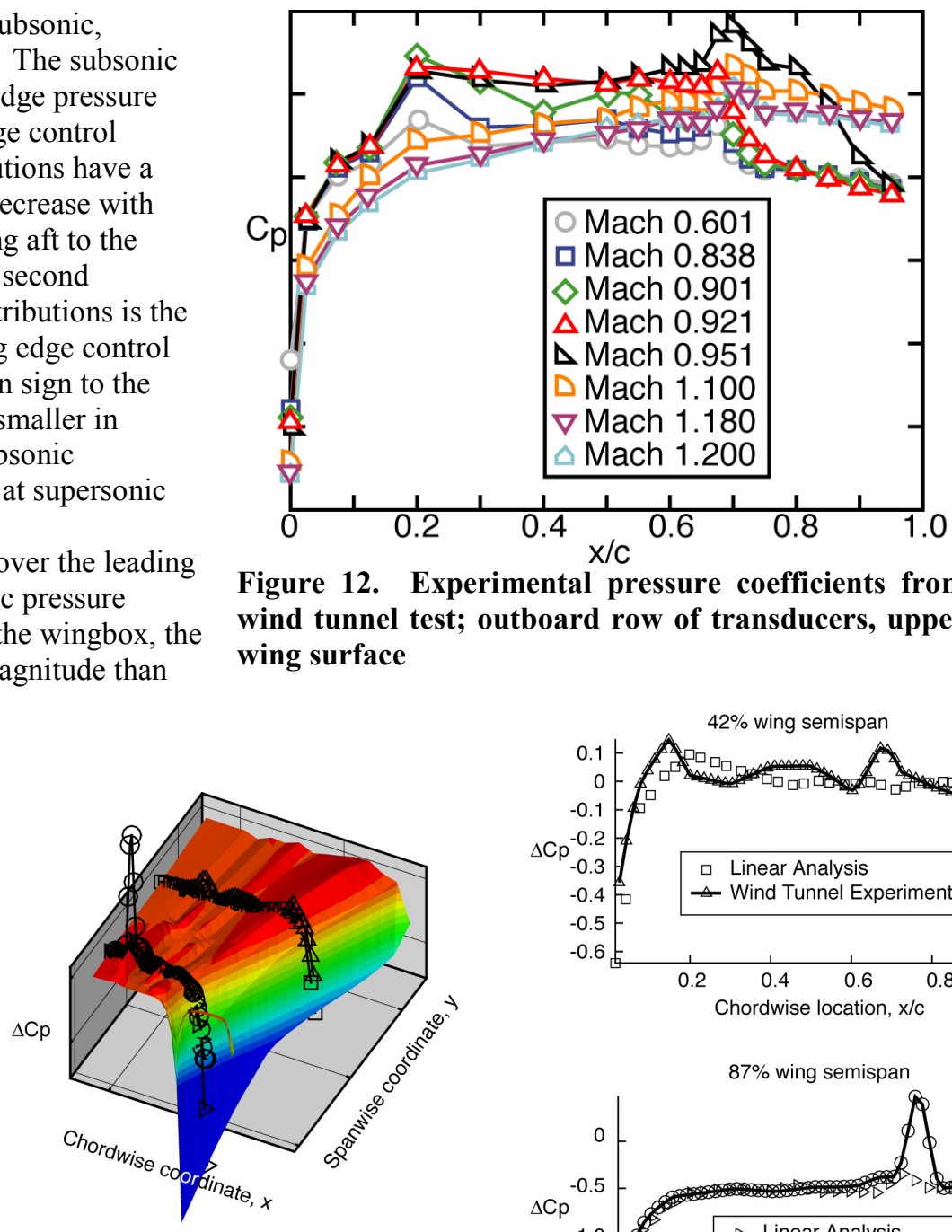

Figure 12. Experimental pressure coefficients from wind tunnel test; outboard row of transducers, upper wing surface control surfaces act in a flow field with almost no pressure gradient. Chordwise oscillations appear over the entire span. The experimental data comparisons show a the leading edge pressure spike that is higher in amplitude and 
terminates closer to the leading edge than the linear analysis. Chordwise oscillations also show up in the experimental data- they are approximately the same amplitude, but are slightly out of phase. The trailing edge control surface hinge line hump appears much more dominant in the experiment than in the linear analysis, particularly at the outboard span station.

Similar data is shown for a supersonic condition, Mach 1.18, in figure 14. Analytically, the pressure peak extends further aft than shown by the experimental data, especially near the wing tip. The analysis shows that a region of high pressure extends from the leading edge at the wing tip, sweeping inboard and aft. Although the slices of analytical data do not appear to correlate well with the experimental data, the carpet plot of the linear analytical results show that the
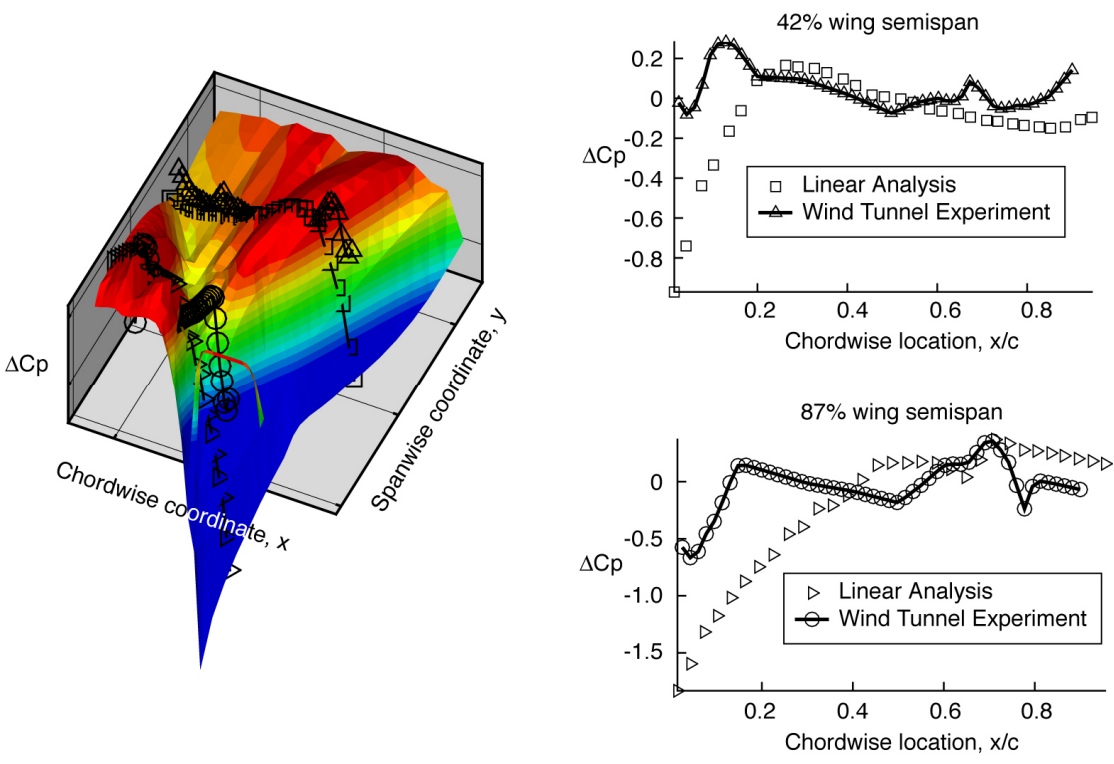

Figure 14. Comparison of wind tunnel data and linear analysis, Mach 0.85 general characteristics in the experimental data are present at nearby span stations.

Pressure slices are plotted for the test conditions described above, comparing them with the pressure distributions produced when the angle of attack and the control surface positions are changed, figures 15 and 16. Figure 17 shows linear analysis and wind tunnel experimental data at Mach .85, while figure 18 shows the data at Mach 1.18. Differential pressure coefficients at the outboard row of pressure transducers are presented. The baseline data in each of the subplots corresponds to the pressure slice data sets in figures 13 and 14, which had no control surface deflection and angle of attack of 0.1 degrees. Subplots $15 \mathrm{a}$ and $16 \mathrm{a}$ show the change in the pressure distributions that occur when the angle of attack is changed to 1 degree. Subplots $15 \mathrm{~b}$ and $16 \mathrm{~b}$ show the changes that occur when the leading edge outboard control surface is deflected 1 degree downward, while subplots $15 \mathrm{c}$ and $16 \mathrm{c}$ show the changes corresponding to 1 degree downward deflection of the trailing edge outboard control surface. Changes to the pressure distributions can be related to the control derivatives, primarily in lift and pitch. With only 2 span stations of measured pressures, it is difficult to glean information pertinent to the rolling moment trends.

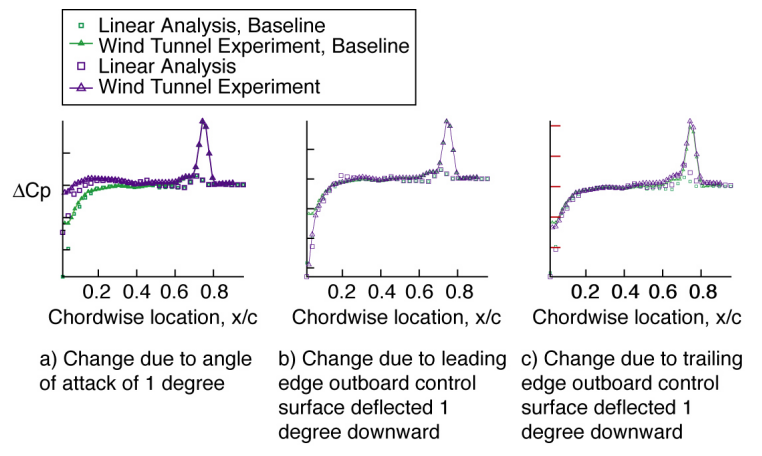

Figure 15. Pressure coefficient changes with angle of attack and control surface deflections at Mach 1.18, 260 psf;

Baseline case: angle of attack 0.1 degrees, all control surfaces 0.0 degrees
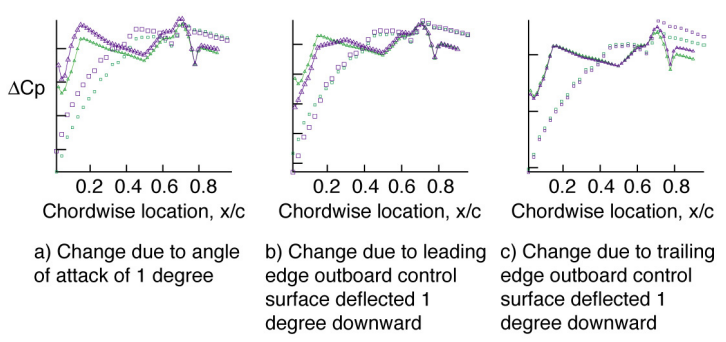

Figure 16. Pressure coefficient changes with angle of attack and control surface deflections at Mach 1.18, 260 psf;

Baseline case: angle of attack 0.1 degrees, all control surfaces 0.0 degrees 


\section{Aerodynamic Center}

The aerodynamic center was computed for the three flexible configuration data sets at each Mach number and dynamic pressure combination. The aerodynamic center was assumed to act at the span station corresponding to the mean aerodynamic chord. The geometry of this span station was used in computing the nondimensionalized results which are shown in figure 17 as functions of Mach number. The linear analysis overpredicts the aftward aerodynamic center shift by approximately $20 \%$.

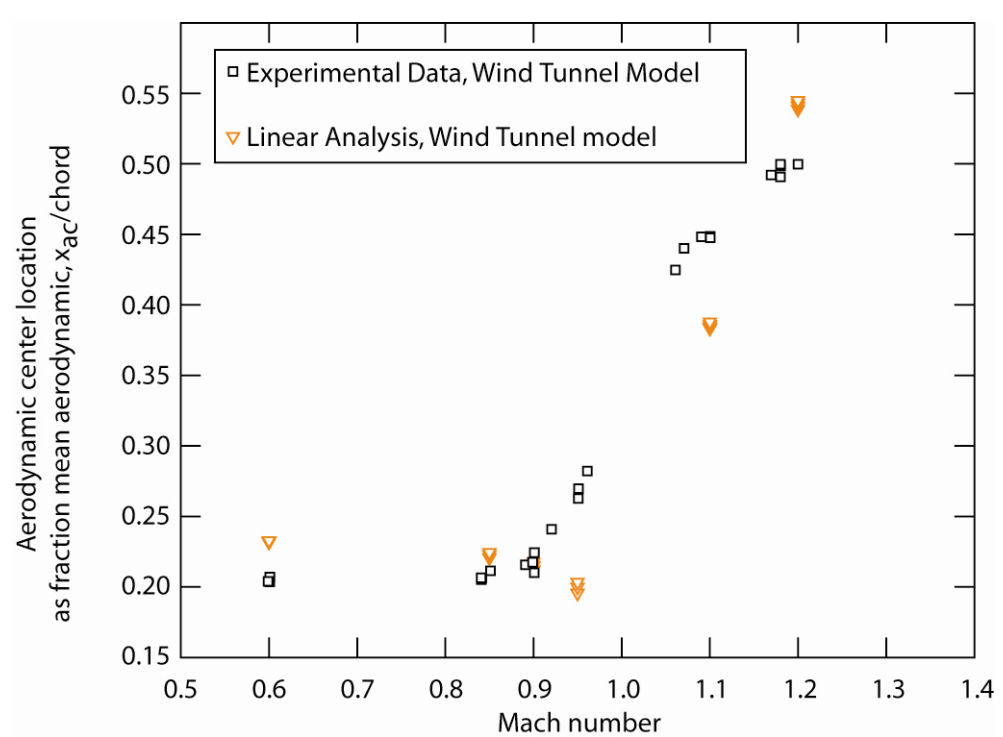

Figure 17. Aerodynamic center location

\section{Concluding Remarks}

Wind tunnel testing of the Active Aerolastic Wing model has been completed. The tasks of interpreting the acquired data and comparing with data from the flight test program and from different analyses have begun. A subset of the data and comparisons have been presented.

The data shown confirm some accepted ideas regarding the transonic behavior of stability and control derivatives of an aeroelastic configuration, such as the increasing authority of leading edge control surfaces and the decreasing authority of trailing edge control surfaces. The data shown also indicate some unexpected behavior, such as rolling moment reversal of a leading edge control surface.

The derivatives due to leading edge control surface deflections tend to exhibit behavior resembling tuck, whereas the trailing edge control surfaces produce a more gradual shift between the subsonic and the supersonic values.

Examining the pressure changes caused by the control surface deflections and by Mach number changes lends additional physical insights into the root causes of the changes in the stability and control derivatives. It is also useful to examine the characteristics as functions of both Mach number and dynamic pressure, parsing the influences of changing aerodynamic pressure distribution and magnitude.

Although there were many instances where linear analysis did not predict the exact behavior of the wind tunnel model, it provided valuable insight into the physics of the problem at all stages: wind tunnel model design, testing, data reduction and interpretation. The linear analysis results were found to be far more representative of the static aeroelastic model behavior than expected in the transonic regime.

\section{Acknowledgements}

The authors wish to gratefully acknowledge the contributions of the technicians, designers and fabrication personnel at NASA LaRC who worked to construct and test the wind tunnel model. Their insights, in addition to their labor, were invaluable in producing the results presented here.

The authors also wish to gratefully acknowledge the AAW engineers and technicians at NASA Dryden Flight Research Center, the Boeing Company, and the Air Force Research Laboratory. The success of the flight test program is the result of many years of work. Additionally, there were stalwart advocates for the wind tunnel model program at all of the partner organizations.

\section{References}

\footnotetext{
${ }^{1}$ Garrick, I.E., "Aeroelasticity- Frontiers and Beyond," $13^{\text {th }}$ Von Karman Lecture, AIAA Journal of Aircraft, Vol 13, No 9, September 1976.
} 
${ }^{2}$ F/A-18 Stability and Control Data Report. Volume I: Low Angle of Attack. MDC 7247, Issued August 31, 1981, revised November 15, 1982.

${ }^{3}$ F/A-18 Aerodynamic Stability and Control and Flying Qualities Report, Volume I: Stability and Control Data. MDC 3957, Issued June 1, 1976, revised March 16, 1981.

${ }^{4}$ Perry, B. III, Cole, S.R., and Miller, G.D., "Summary of an active flexible wing program," AIAA Journal of Aircraft, Vol 32, No 1, January-February 1995.

${ }^{5}$ Pendleton, E. W., Bessette, D., Field, P.B., Miller, G. D., and Griffin, K.E., “Active aeroelastic wing flight research program and model analytical development," AIAA Journal of Aircraft, Vol 37, No. 4, July-August 2000.

${ }^{6}$ Abel, I. "Evaluation of a technology for determining airplane aileron effectiveness and roll rate by using a static aeroelastically scaled model", NASA TN D5538, November 1969.

${ }^{7}$ Heeg, J., Spain, C.V. and Rivera, J.A., "Wind Tunnel to Atmospheric Mapping for Static Aeroelastic Scaling," $45^{\text {th }}$ AIAA/ASME/ASCE/AHS.ASC Structures, Structural Dynamics and Materials Conference, April, 2004, Palm Springs, California.

${ }^{8}$ Molyneux, W.G., “Aeroelastic modeling,” RAE Technical note number Structures 353, March 1964.

${ }^{9}$ Burner, A.W. and Liu, T., "Videogrammetric Model Deformation Measurement Technique," AIAA Journal of Aircraft, Vol 38, No 4, July 2001

${ }^{10}$ Florance, J.R., Spain, C.V, and Heeg, J, Ivanco, T.G, Wieseman, C.D., "Variable Stiffness Spar Wind Tunnel Model Development and Testing," $45^{\text {th }}$ AIAA/ASME/ASCE/AHS.ASC Structures, Structural Dynamics and Materials Conference, April, 2004, Palm Springs, California

${ }^{11}$ Wieseman, C.D., Spain, C.V., Silva, W.A. and Heeg, J., "Transonic Small Disturbance and Linear Analysis for the Active Aeroelastic Wing Program," $46^{\text {th }}$ AIAA/ASME/ASCE/AHS/ASC Structures, Structural Dynamics and Materials Conference, April, 2005, Austin, Texas

${ }^{12}$ Rodden, William P., and Erwin J. Johnson. MSC/NASTRAN Aeroelastic Analysis User's Guide. Version 68, 1994.

${ }^{13}$ Rodden, W. P., Giesing, J.P., and Kalman, T. P., "New Developments and Applications of the Subsonic DoubletLattice Method for Nonplanar Configurations," AGARD Symposium on Unsteady Aerodynamics for Aeroelastic Analyses of Interfering Surfaces, Paper number 4, November 1970.

${ }^{14}$ Chen, P.C, and Liu, D.D., "A Harmonic Gradient Method for Unsteady Supersonic Flow Calculations,” Journal of Aircraft, Vol. 22, No. 5, May 1985.

${ }^{15}$ Roskam, J. "Airplane flight dynamics and automatic flight controls, part I," pp 71-81, Roskam Aviation and Engineering Corporation 1979. 